\title{
Characterization of Tannery Wastewater and Detoxification Potentials of Polysiloxane Immobilized Ligand Systems on Selected Heavy Metals
}

\author{
Habila $B^{1 *}$, Chidiebere $E^{2}$, Simon Moses $S^{3}$, Uwanta $\mathrm{EJ}^{4}$, Simon $\mathrm{A}^{1}$, Shekarri \\ TNB $^{1}$ and Gaiya JD ${ }^{1}$ \\ ${ }^{1}$ Nigerian Institute of Leather and Science Technology, Nigeria \\ ${ }^{2}$ Department of Industrial Chemistry, Enugu State University of Science and Technology, \\ Nigeria \\ ${ }^{3}$ National Institute of Hospitality and Tourism Studies Kaduna Training Centre, Nigeria \\ ${ }^{4}$ Department of Chemistry, Akwa Ibom State University, Nigeria
}

\section{Research Article \\ Volume 5 Issue 1}

Received Date: March 09, 2021

Published Date: March 25, 2021

DOI: $10.23880 / p s b j-16000166$

*Corresponding author: Habila Bulus, Nigerian Institute of Leather and Science Technology, P M B 1034, Zaria, Nigeria, Tel: 08030758059; Email: bulus1973@gmail.com

\section{Abstract}

Tanning industry has the highest toxic intensity per unit out- put and requires large amount of water, during tanning chemicals are added per ton of hides such as acids, alkalis, tannins (natural or synthetic), solvents, sulphides, dyes, surfactants, heavy metals (chromium salts), and other auxiliaries. Not more than $20 \%$ of the chemicals are absorbed by leather; the remainder flows out with the effluent and mixture of many compounds may complicate the wastewater treatment such as. Tannery effluent samples were collected at Challawa Industrial Area in Kano and characterized as follows (mg/l): total dissolved solids $7525 \pm 620$; total suspended solids $3963 \pm 816$; chemical oxygen demand $6847 \pm 1721$; biochemical oxygen demand $2906 \pm$ 115 while, $\mathrm{pH} 7.8$ and temperature $28 \pm 1\left({ }^{\circ} \mathrm{C}\right)$ were recorded respectively. The effluent contained the following concentrations in ppm: $\mathrm{Cr}^{3+}$ (144.344), $\mathrm{Fe}^{3+}$ (49.420), $\mathrm{Cu}^{2+}(1.076), \mathrm{Pb}^{2+}(1.766)$ and $\mathrm{Zn}^{2+}(0.238)$ respectively. Conventional methods used in the tannery wastewater treatments have limitations such as production of toxic sludge and inability to remove heavy metals at trace level. This prompted the use of polymeric modified surfaces with excellent thermal, mechanical and chemical stability properties such as polysiloxane immobilized with ligands as a recyclable extractants for heavy metals. These immobilized ligand systems were synthesized directly by sol gel/chemical modification namely: Polysiloxane Immobilized Thiosalicylic Acid Ligand System (PITSLS), Polysiloxane Immobilized Thiolactic Acid Ligand System (PITLLS), Polysiloxane Immobilized Mercaptoethanol Ligand System (PIMLS), Polysiloxane Immobilized Thiosalicylic-Thiolactic Bi-Ligand System (PITSTLBLS), Polysiloxane Immobilized Thiosalicylic-Mercaptoethanol Bi-Ligand System (PITSMCBLS), Polysiloxane Immobilized ThiolacticMercaptoethanol Bi-Ligand System (PITLMCBLS) and used in their pure and regenerated matrices for detoxification of raw and buffered tannery wastewater. The results obtained shows that they have good adsorption potentials for the selected heavy metals and can be used in the tannery for detoxification process.

Keywords: Characterization; Tannery wastewater; Polysiloxane immobilized ligands; Detoxification; Heavy metals 


\section{Introduction}

Tanneries are typically characterised as pollution intensive industrial complexes which generate wastewater. Two methods are employed in tanning of raw hides and skins namely: vegetable and chrome tanning. Most of the modern tanneries adopt the chrome tanning process because of speed, low cost and greater stability to the resultant leather $[1,2]$. The production processes can be divided into four categories: (i) Hides and skin storage and beam house operations (ii) Tan yard operations (iii) Post tanning operations and (iv) Finishing operations [3].

Tanning industry has the highest toxic intensity per unit out-put [4], and requires large amount of water, about $35 \mathrm{~L}$ of water is consumed per kilogram of raw hide or skin processed, and an average of 35,000 $\mathrm{L}$ of wastewater is produced per ton of raw hide [5]. During tanning alone about $300 \mathrm{~kg}$ of chemicals are added per ton of hides with attendant $150 \mathrm{~kg}$ of leather, $150 \mathrm{~kg}$ of splits and $700 \mathrm{~kg}$ of liquid and solid waste are produced [4,6-8]. Not more than $20 \%$ of the chemicals are absorbed by leather; the remainder flows out with the effluent [9], and mixture of many compounds may complicate the wastewater treatment such as: acids, alkalis, chromium salts, tannins (natural or synthetic), solvents, sulphides, dyes, surfactants, auxiliaries, heavy metals, and other compounds which are used to transform a hide or skin to leather, are not completely fixed to the collagen fibres and the surface of the product, thus remaining free in the effluent $[10,11]$. The characteristics of tannery wastewater vary considerably from tannery to tannery depending upon the size of the tannery, chemicals used, amount of water used and the final products produced. Waste generated contains heavy metals, toxic chemicals, chloride, lime, high dissolved and suspended salts and other pollutants $[10,11]$. These effluents have various permissible limits of discharge $[12,13]$.

Wastewater is characterised mainly by measurement of biochemical oxygen demand (BOD), chemical oxygen demand (COD), suspended solids (SS) and total dissolved solids (TDS), chromium and sulphides [14]. These effluents are basic, dark brown or greenish in colour [15]. These wastes encroach into rivers and agricultural lands $[1,16,17]$. The release of these materials into the environment cause serious health problems due their toxicity, non- biodegradable nature, bio-accumulating tendency [18-20] to the terrestrial, aquatic and aerial environments. The presence of increase heavy metals such as cadmium, mercury, lead, copper, zinc, nickel, chromium poses significant risk to soil, water and human health $[18,19,21]$. Hence the use of adsorbents to detoxify these heavy metals from the wastewater becomes imperative. Conventional methods used in the tannery wastewater treatments have limitations such as production of toxic sludge [22] and inability to remove heavy metals at trace level. There is need for innovative technologies which require low maintenance, high energy efficiency, low cost and better operational techniques than the conventional methods, this prompted the use of polymeric modified surfaces with excellent thermal, mechanical and chemical stability properties such as polysiloxane functionalized or immobilized with ligands [23] have been employed as a recyclable extractants for heavy metals.

\section{Methodology}

\section{Location of the Study Area}

Kano state covers an area extending between latitudes $120^{\circ} 40^{1}$ and $100^{0} 30^{1}$ and longitudes $70^{\circ} 40^{1}$ and $90^{\circ} 30^{1}$. Climate is tropical wet and dry with mean annual rainfall of $850 \mathrm{~mm}$, and a population of 9.3 million, it is a flat city drained by the Jakara river and several streams (Niger river watershed) and River Challawa (Lake Chad watershed) all are severely polluted by urban and industrial effluents. Kumbotso local government is the area of study and it lies between latitudes $11^{\circ} 50^{\prime} \mathrm{S}$ to $12^{\circ} \mathrm{N}$ and longitude $8^{\circ} 24^{\prime} \mathrm{W}$ to $8^{\circ} 40^{\prime}$ E. It falls within the Kano State settlement zone bordering the south and west by Madobi Local Government Area, in the Northern west; Rimin-gado, in the North by Gwale and East by Tarauni local government areas respectively [2426] as presented in Figure 1.

\section{Tannery Effluent Sample Collection and Preservation}

Samples were collected three times at one-day interval (7:00 am daily in the month of February, 2017) at a point where three effluent channels confluence before mixing with Challawa River as presented in Figure 1.0., and Plates I - IV respectively.

\section{Physico-Chemical Analysis of Tannery Wastewater}

The $\mathrm{pH}$ and Temperature of the effluent were analysed by electronic method using JENWAY 3505 Multi-ameter on site [27] respectively.

\section{Determination of Total Dissolved Solid}

Empty evaporating dish (cleaned porcelain dish) that was oven dried at $180^{\circ} \mathrm{C}$ for $1 \mathrm{~h}$, cooled and weighed, 50 $\mathrm{cm}^{3}$ of unfiltered wastewater was dispensed into the dish, evaporated to dryness on a steam bath and further placed in 
an oven (Gallenkamp) at $105^{\circ} \mathrm{C}$ and evaporated for $60 \mathrm{~min}$ to a constant weight $[28,29]$.

\section{Determination of Total Suspended Solid}

Empty evaporating dish (cleaned porcelain dish) that was oven dried at $180^{\circ} \mathrm{C}$ for $1 \mathrm{~h}$, cooled and weighed, $50 \mathrm{~cm}^{3}$ of wastewater was filtered through Whatman filter paper and the residue collected and the filtrate evaporated to dryness on a steam bath and further placed in an oven (Gallenkamp) at $105^{\circ} \mathrm{C}$ evaporated for $60 \mathrm{~min}$ to a constant weight $[28,29]$.

\section{Determination of Biochemical Oxygen Demand (BOD)}

The biochemical oxygen demand of the tannery wastewater was determined following the standard methods described in APHA [29] $150 \mathrm{~cm}^{3}$ of the sample was incubated at $20^{\circ} \mathrm{C}$ for 5 days in airtight bottles. The $\mathrm{BOD}_{5}$ was calculated from the difference between the dissolved oxygen (DO) values measured before and after incubation.

\section{Determination of Dissolved Oxygen}

Dissolved oxygen was measured by titration with standard thiosulfate solution. $150 \mathrm{~cm}^{3}$ of the tannery wastewater was treated with $1.5 \mathrm{~cm}^{3}$ of manganese (II) sulphate $\left(\mathrm{MnSO}_{4} \cdot 4 \mathrm{H}_{2} \mathrm{O}\right)$ solution and $1.5 \mathrm{~cm}^{3}$ alkaline iodine solutions. The bottled containers were stoppered to avoid the inclusion of air bubbles and thoroughly shaken. The resultant precipitate was allowed to settle completely leaving a clear supernatant. The liberated iodine was titrated with 0.0125 $\mathrm{mol} / \mathrm{dm}^{3}$ sodium thiosulfate, using $2 \mathrm{~cm}^{3}$ starch solution as indicator and a blank test conducted [30].

\section{Determination of Chemical Oxygen Demand (COD)}

Quantitatively, $5 \mathrm{~cm}^{3}$ of tannery effluent sample was dispensed into a flask; $0.2 \mathrm{~g}$ of mercury (II) sulphate was added and shaken thoroughly. The flask was then immersed in a cold running water and $5 \mathrm{~cm}^{3}$ of $0.125 \mathrm{~N}$ potassium dichromate $\left(\mathrm{K}_{2} \mathrm{Cr}_{2} \mathrm{O}_{7}\right)$ was added, followed by $10 \mathrm{~cm}^{3}$ of concentrated $\mathrm{H}_{2} \mathrm{SO}_{4}$ and $1 \mathrm{~cm}^{3}$ of silver sulphate solution (COD acid) were added shaken thoroughly and kept in a flask, refluxed with some anti-bumping granules and boiled for $2 \mathrm{~h}$. After cooling, $45 \mathrm{~cm}^{3}$ of distilled water was added. Three (3) drops of iron (II) 1, 10-phenanthroline indicator solution were added and the residual dichromate sample was titrated against Ferrous Ammonium Sulphate 0.125 $\mathrm{mol} / \mathrm{dm}^{3}$. The end point was reddish brown in colour. A blank determination was carried out in a similar manner using $5 \mathrm{~cm}^{3}$ of distilled water instead of the tannery wastewater sample [30].

\section{Synthesis of Polysiloxane Immobilized Ligand Systems Used}

Synthesis of 3-Chloropropylpolysiloxane (3-CPP), functionalized 3-Chloropropylpolysiloxane Matrix (F 3-CPP), (PITSLS), (PITLLS), (PIMLS), (PITSTLBLS), (PITSMCBLS), (PITLMCBLS) were synthesized based on the methods of ElNahhal [31], Salman and Nizam [32], Nizam [33], Bulus, et al. [34] with modifications.

\section{Re-generation and Recyclability of used Polysiloxane Immobilized Ligand Systems}

The sorbents used for the tannery wastewater batch experiments were re-generated by shaking with $5 \mathrm{~cm}^{3}$ of $\mathrm{HNO}_{3}\left(1.0 \mathrm{~mol} / \mathrm{dm}^{3}\right)$ for $60 \mathrm{~min}$, filtered, rinsed three times with de-ionized water, methanol and diethyl ether and dried $(333 \mathrm{~K}$ for $3 \mathrm{~h}$ ) for next extraction cycle (Abdussalam, et al. [35]; Bernard and Jimoh [36]) and their efficiency for detoxification of heavy metals were compared with the original adsorbents

\section{Detoxification Potentials of Polysiloxane immobilized ligands on Raw Tannery Wastewater as Obtained (pH 7.8)}

The methods of Onyeji and Aboje [37], Horsfall, et al. [38], and Vasanth and Kumar [39] were adopted. A volume of $50 \mathrm{~cm}^{3}$ solution at $\mathrm{pH} 7.8$, were collected into six $(150$ $\mathrm{cm}^{3}$ ) conical flasks and modified using $20 \mathrm{mg}$ (125-150 $\mu \mathrm{m})$ of polysiloxane immobilized thiosalicylic ligand system in an Orbital shaker (SI-300R) at 100 oscillations for $2 \mathrm{~h}$ at $303 \mathrm{~K}$. The resultant solutions were filtered using Whatman No.41 and the residual metal $\left(\mathrm{Cr}^{3+}, \mathrm{Fe}^{3+}, \mathrm{Cu}^{2+}, \mathrm{Pb}^{2+}\right.$ and $\mathrm{Zn}^{2+}$ ) concentrations analysed using Agilent MPAES-4200. This protocol was repeated separately for polysiloxane immobilized thiolactic, mercaptoethanol, thiosalicylicthiolactic, thiosalicylic-mercaptoethanol, thiolacticmercaptoethanol ligands and their regenerated adsorbents (recycled) in detoxifying heavy metals ions in tannery wastewater respectively.

\section{Detoxification Potentials of Polysiloxane immobilized ligands on Raw Tannery Wastewater Buffered to pH 6.0}

The methods of Onyeji and Aboje [37]; Horsfall, et al. [38]; and Vasanth and Kumar [39] were adopted. A volume of $50 \mathrm{~cm}^{3}$ solution buffered to $\mathrm{pH} 6.000$, were collected into six $\left(150 \mathrm{~cm}^{3}\right)$ conical flasks and modified using $20 \mathrm{mg}$ (125-150 
$\mu \mathrm{m})$ of polysiloxane immobilized thiosalicylic ligand system in an Orbital shaker (SI-300R) at 100 oscillations for $2 \mathrm{~h}$ at $303 \mathrm{~K}$. The resultant solutions were filtered using Whatman No.41 and the residual metal $\left(\mathrm{Cr}^{3+}, \mathrm{Fe}^{3+}, \mathrm{Cu}^{2+}, \mathrm{Pb}^{2+}\right.$ and $\mathrm{Zn}^{2+}$ ) concentrations analysed using Agilent MPAES-4200. This protocol was repeated separately for polysiloxane immobilized thiolactic, mercaptoethanol, thiosalicylicthiolactic, thiosalicylic-mercaptoethanol, thiolacticmercaptoethanol ligands respectively (Figure 1-4).
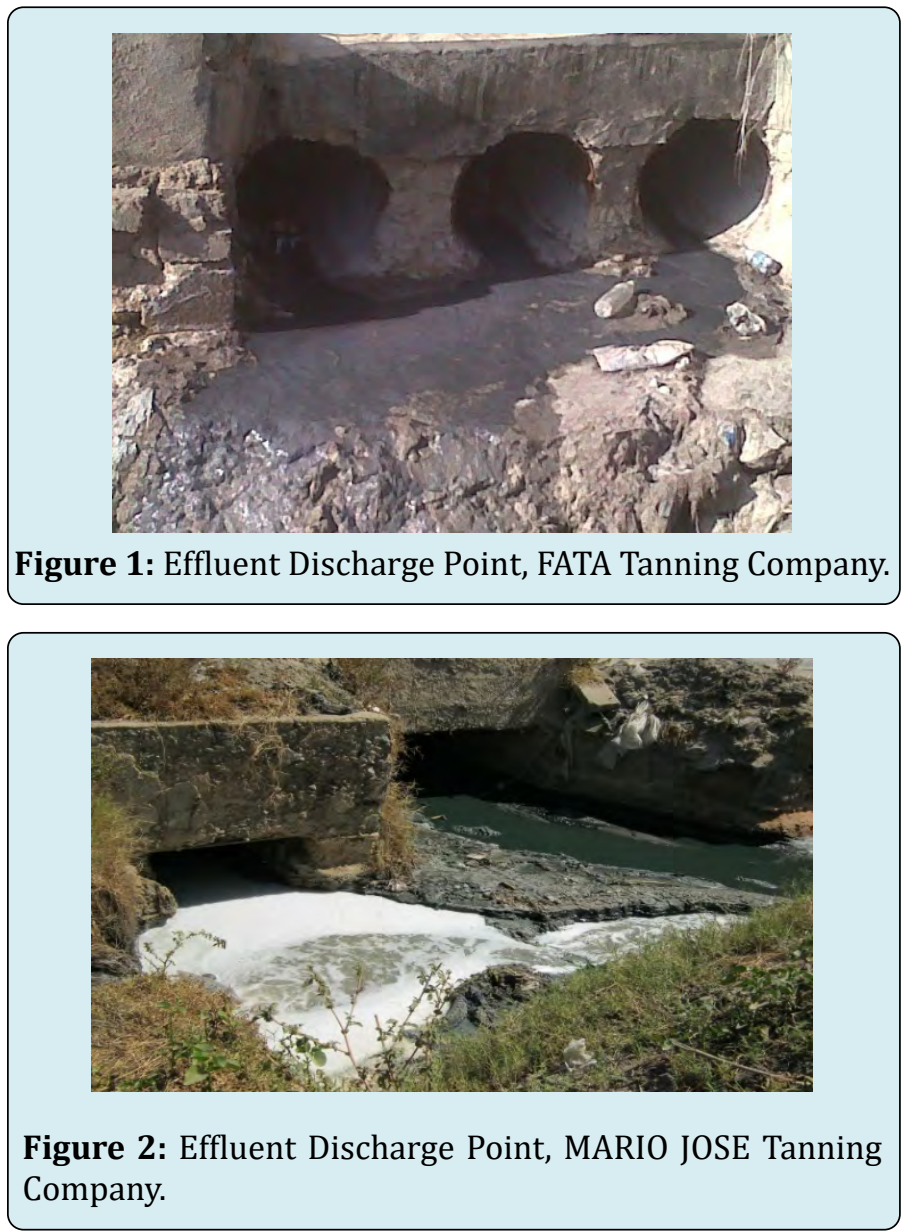

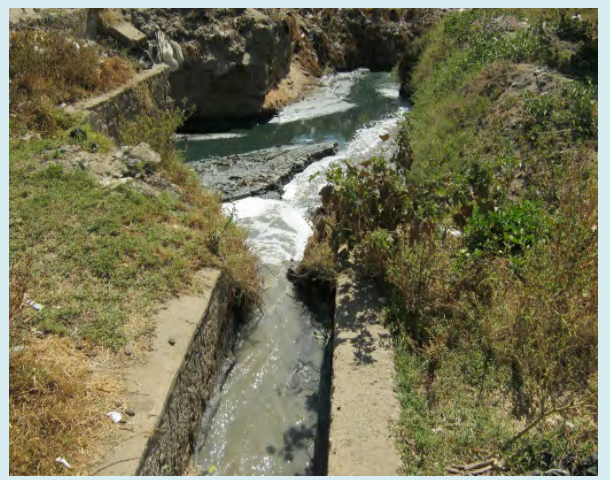

Figure 3: Effluent Discharge Point, MAHAZA Tanning Company.

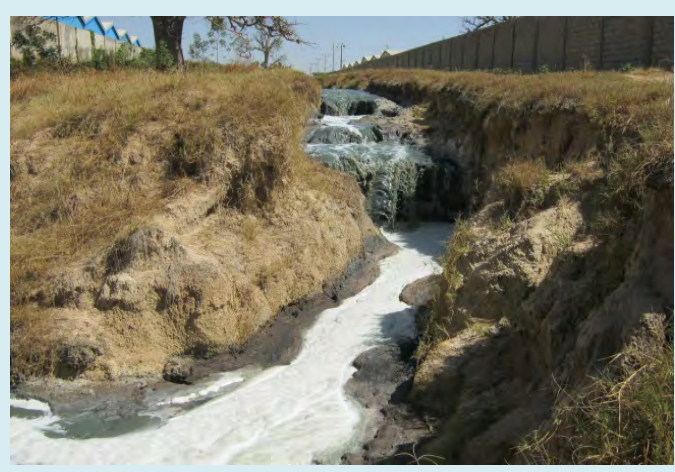

Figure 4: Effluent Discharge Collection Point.

\section{Results and Discussions}

\section{Some Physico-chemical Parameters of the Tannery Wastewater}

The Physico-chemical parameters of the tannery wastewater analysed include the following: colour, odour, $\mathrm{pH}$, temperature, total dissolved solids, total suspended solids, biochemical oxygen demand and chemical oxygen demand. The results are presented in Table 1-4.

\begin{tabular}{|c|c|c|c|c|}
\hline \multicolumn{3}{|c|}{ Tannery Wastewater } & B & C \\
\hline Parameters & Units & A & & \\
\hline Colour & Brownish green & & & \\
\hline Odour & Objectionable & 7.2 & 7.9 & 8.5 \\
\hline $\mathrm{pH}$ & $\mathrm{NU}$ & 27 & 29 & 28 \\
\hline Temperature & $\mathrm{oC}$ & 6891 & 7556 & 8130 \\
\hline TDS & $\mathrm{mg} / \mathrm{l}$ & 3681 & 4884 & 3326 \\
\hline TSS & $\mathrm{mg} / \mathrm{l}$ & 2788 & 2914 & 3018 \\
\hline BOD & $\mathrm{mg} / \mathrm{l} \mathrm{O2}$ & 8321 & 4974 & 7348 \\
\hline COD & $\mathrm{mg} / \mathrm{l} \mathrm{O2}$ & & & \\
\hline
\end{tabular}

Table 1: Physico-Chemical Characteristics of Tannery Wastewater; Note* NU= No Unit; A, B and C are samples collected 
Physical Science \& Biophysics Journal

\begin{tabular}{|c|c|c|c|c|c|c|c|c|c|c|}
\hline & \multicolumn{2}{|c|}{ Chromium } & \multicolumn{2}{c|}{ Iron } & \multicolumn{2}{c|}{ Copper } & \multicolumn{2}{c|}{ Lead } & \multicolumn{2}{c|}{ Zinc } \\
\hline Init. Co & \multicolumn{2}{|c|}{144.344} & \multicolumn{2}{|c|}{49.42} & \multicolumn{2}{c|}{1.076} & \multicolumn{2}{c|}{1.766} & \multicolumn{2}{c|}{0.238} \\
\hline Orig. Ads & Conc. & \%Ads & Conc. & \%Ads & Conc. & \%Ads & Conc. & \%Ads & Conc. & \%Ads \\
\hline aa & 0.072 & 99.95 & 0.091 & 99.816 & 0.095 & 91.171 & 0.158 & 91.053 & 0.023 & 90.336 \\
\hline bb & 0.108 & 99.925 & 0.136 & 99.725 & 0.062 & 94.238 & 0.146 & 91.733 & -0.007 & 100 \\
\hline cc & 0.097 & 99.933 & 0.122 & 99.753 & 0.047 & 95.632 & 0.109 & 93.828 & -0.009 & 100 \\
\hline dd & 0.035 & 99.976 & 0.105 & 99.788 & 0.024 & 97.77 & 0.08 & 95.47 & -0.01 & 100 \\
\hline ee & 0.057 & 99.961 & 0.099 & 99.8 & 0.032 & 97.026 & 0.097 & 94.507 & -0.007 & 100 \\
\hline ff & 0.065 & 99.955 & 0.095 & 99.808 & 0.028 & 97.398 & 0.085 & 95.187 & -0.011 & 100 \\
\hline
\end{tabular}

Table 2: Detoxification Potentials of Polysiloxane immobilized ligands on Raw Tannery Wastewater in ppm (pH 7.8). $\mathrm{aa}=$ PITSLS, $\mathrm{bb}=$ PITLLS, $\mathrm{cc}=$ PIMLS, $\mathrm{dd}=$ PITSTLBLS, ee = PITSMCBLS, $\mathrm{ff}=$ PITLMCBLS, Init. Co = Initial Concentration $(\mathrm{ppm})$, Orig Ads $=$ Original Adsorbent, $\%$ Ads $=\%$ Adsorption

\begin{tabular}{|c|c|c|c|c|c|c|c|c|c|c|}
\hline & \multicolumn{2}{|c|}{ Chromium } & \multicolumn{2}{c|}{ Iron } & \multicolumn{2}{c|}{ Copper } & \multicolumn{2}{c|}{ Lead } & \multicolumn{2}{c|}{ Zinc } \\
\hline Init. Co & \multicolumn{2}{|c|}{144.344} & \multicolumn{2}{|c|}{49.42} & \multicolumn{2}{c|}{1.076} & \multicolumn{2}{c|}{1.766} & \multicolumn{2}{c|}{0.238} \\
\hline Orig. Ads & Conc. & \%Ads & Conc. & \%Ads & Conc. & \%Ads & Conc. & \%Ads & Conc. & \%Ads \\
\hline aa & 0.104 & 99.927 & 0.364 & 99.263 & 0.001 & 99.907 & 0.086 & 95.13 & 0.013 & 94.537 \\
\hline bb & 0.016 & 99.988 & 0.601 & 98.783 & 0.002 & 99.814 & 0.033 & 98.131 & -0.507 & 100 \\
\hline cc & 0.041 & 99.971 & 1.24 & 97.49 & 0.002 & 99.814 & 0.84 & 52.434 & 0.001 & 99.579 \\
\hline dd & 0.03 & 99.979 & 1.731 & 96.497 & 0.003 & 99.721 & 0.023 & 98.697 & 0.02 & 91.596 \\
\hline ee & 0.042 & 99.97 & 3.04 & 93.848 & 0.005 & 99.999 & 0.05 & 97.168 & 0.017 & 92.857 \\
\hline ff & 0.07 & 99.951 & 2.424 & 95.095 & 0.004 & 96.628 & 0.012 & 99.32 & 0.018 & 92.436 \\
\hline
\end{tabular}

Table 3: Detoxification Potentials of Polysiloxane immobilized ligands on Raw Tannery Wastewater (ppm) Buffered to pH 6.0. $\mathrm{aa}=$ PITSLS, $\mathrm{bb}=$ PITLLS, $\mathrm{cc}=$ PIMLS, $\mathrm{dd}=$ PITSTLBLS, ee = PITSMCBLS, $\mathrm{ff}=$ PITLMCBLS, Init. Co $=$ Initial Concentration (ppm), Orig Ads = Original Adsorbent, \%Ads = \% Adsorption

\begin{tabular}{|c|c|c|c|c|c|c|c|c|c|c|}
\hline & \multicolumn{2}{|c|}{ Chromium } & \multicolumn{2}{c|}{ Iron } & \multicolumn{2}{c|}{ Copper } & \multicolumn{2}{c|}{ Lead } & \multicolumn{2}{c|}{ Zinc } \\
\hline Init. Co & \multicolumn{2}{|c|}{144.344} & \multicolumn{2}{|c|}{49.42} & \multicolumn{2}{c|}{1.076} & \multicolumn{2}{c|}{1.766} & \multicolumn{2}{c|}{0.238} \\
\hline Recyc. Ads & Conc. & \%Ads & Conc. & \%Ads & Conc. & \%Ads & Conc. & \%Ads & Conc. & \%Ads \\
\hline aaRG & 2.556 & 98.229 & 0.258 & 99.478 & 0.182 & 83.086 & 0.453 & 74.349 & 0.032 & 86.555 \\
\hline bbRG & 0.092 & 99.936 & 0.136 & 99.725 & 0.089 & 91.729 & 0.313 & 82.276 & 0.02 & 91.597 \\
\hline ccRG & 3.555 & 97.537 & 0.426 & 99.138 & 0.238 & 77.881 & 0.589 & 66.648 & 0.037 & 84.454 \\
\hline ddRG & 2.64 & 98.171 & 0.136 & 99.725 & 0.103 & 90.428 & 0.433 & 75.481 & 0.049 & 79.412 \\
\hline eeRG & 3.136 & 97.827 & 0.261 & 99.472 & 0.204 & 81.041 & 0.528 & 70.102 & 0.059 & 75.21 \\
\hline ffRG & 5.23 & 96.377 & 0.473 & 99.043 & 0.259 & 75.929 & 0.774 & 56.172 & 0.552 & -131.933 \\
\hline
\end{tabular}

Table 4: Detoxification Potentials of Regenerated Polysiloxane Immobilized Ligands on Raw Tannery Wastewater. aaRG $=$ PITSLS, $b b R G=$ PITLALS, $c c R G=$ PIMLS, ddRG $=$ PITSTLBLS, eeRG = PITSMCBLS, ffRG $=$ PITLMCBLS, \%Ads = Percentage adsorption, Recyc $=$ Recycled, Init. $\mathrm{Co}=$ Initial Concentration $(\mathrm{ppm}), \mathrm{RG}=$ Regenerated

\section{pH Level}

Acceptable limits for the discharge of wastewater to both surface water sewers are found ranging from between pH 5.5-10.0 [40]. Although tighter limits are often set, there is always greater tolerance to the alkaline side this is because carbon dioxide from the atmosphere and from biological processes in healthy surface water system tends to lower pHs very effectively to neutral conditions. At the time of sample collection, the $\mathrm{pH}$ of the wastewater was 7.8 in Table 1.0.
The $\mathrm{pH}$ range was found to be within the acceptable limit, which accounts for its low concentration in the solution but was within the ranges $(7.2-9.2)$ reported by Kurt, et al. [41]; Mandal, et al. [42]; and Song, et al. [43] and 5.5 - 9.0 (WHO, 2002). Common effluent treatment plants prefer discharges to be on the alkaline side as the corrosive effect on concrete is reduced. Metals tend to remain insoluble and more inert, and the evolution of hydrogen sulphide is minimised [40] If the $\mathrm{pH}$ of surface water is moved too far either away from the $\mathrm{pH}$ range 6.5-7.5, then there is loss of more sensitive fish or 
plant life.

\section{Temperature}

The temperature of tannery wastewater plays a vital role in the solubility of salts used in production such as: ammonium chloride, ammonium sulphates, sodium chloride as well as dissociation of dissolved salts thereby increasing electrical conductivity value. Temperature also affects the potential of $\mathrm{pH}$. Hence, it was measured in-situ after immersion in the wastewater for a period of $10 \mathrm{~min}$, the temperature was found to be $28 \pm 1{ }^{\circ} \mathrm{C}$ in Table 1.0. Which was within the limit of $25-31{ }^{\circ} \mathrm{C}$ reported by Jahan, et al. [22] and $25-40$ by Islam, et al. [5].

\section{Total Dissolved Solids (TDS)}

TDS is the sum of the cations and anions. It is an important water quality parameter. An increase in salinity causes an increase in the osmotic pressure of the soil solution, resulting in a reduced availability of water for plant consumption and possible retardation of plant growth. In the case of tannery waste water, the colloidal form, solid impurities, dissolved species, nature and quality of the hides and skins processed during soaking and pickling may cause high turbidity in the receiving streams as a result of high salt content. The result in Table 1.0 gave $7525 \pm 620 \mathrm{mg} / \mathrm{L}$ which is low compared to $21300 \mathrm{mg} / \mathrm{L}$ by Jahan, et al. [22] 21,620 mg/L by Mandal, et al. [42]; 10,000 mg/L by Haydar and Aziz [44] and is not in agreement with the permissible limit of discharge of 2100 $\mathrm{mg} / \mathrm{L}$ [45]. The probable reason for the fluctuation of value of total solid and subsequently the value of dissolved solids Ions and ionic compounds making up TDS. The main components of TDS are inorganic salts and are viewed as mainly sodium chloride, ammonium sulphate and sodium sulphate $[40,46]$, but any ion that is present contributes to the total. This is due to content collision of the colloidal particles and the rate of aggregated process influenced by the $\mathrm{pH}$ of the tannery wastewater.

\section{Total Suspended Solids (TSS)}

Suspended solids do not necessarily mean that they are floating matters and remain on top of surface water. They are under suspension and remain in water sample. The TSS plays an important role in water and wastewater treatment. Their presence in water causes depletion of oxygen level. The permissible limit for discharge is $600 \mathrm{mg} / \mathrm{L} \mathrm{[22]} \mathrm{but} \mathrm{this}$ work gave $3963 \pm 816 \mathrm{mg} / \mathrm{L}$ in Table 1.0, which is above the limit. This could be attributed to the composition of tanning chemicals and the raw hides and skins processed, trimmings, shavings, fleshings and adhering dungs [46]. These factors could lead to turbidity resulting in poor photosynthetic activity in aquatic life, clogging of gills and respiratory surfaces in fishes [5].

\section{Chemical Oxygen Demand (COD)}

The COD test is used to determine the oxygen required for chemical oxidation of organic matter with the help of strong chemical oxidant. The COD test is used to measure pollution of domestic and industrial wastewater in terms of equality of oxygen required for oxidation of organic matter to produce $\mathrm{CO}_{2}$ and $\mathrm{H}_{2} \mathrm{O}$. Almost all organic compounds can be oxidised under acidic condition. COD is useful in pin-pointing toxic conditions and presence of biological resistance substances. The permissible limit of discharge is at the range of $300-3000 \mathrm{mg} / \mathrm{L}$ [5]. The result obtained in Table 1.0, was higher than the set limit with the value of $6847 \pm 1721$ $\mathrm{mg} / \mathrm{L}$ this indicates that the effluent is unsuitable for the existence of the aquatic organisms due to the reduction in the dissolved content. These results are always higher than the $\mathrm{BOD}_{5}$ results. As a rule of the thumb the ratio between COD:BOD in untreated effluent samples varies between 2:1 and 3:1 these ratios are dependent upon the chemicals used in leather making processes and the rate of biodegradability [39].

\section{Biological Oxygen Demand (BOD)}

BOD is a method of estimating the power of the effluent to reduce the oxygen content of water. Spent deliming liquors, which are discharged as waste also contribute significant pollution load. Increase in BOD content is also associated with liming, fleshing, chrome and vegetable tanned wastewater. The values obtained in Table 1.0, gave $2906 \pm 115 \mathrm{mg} / \mathrm{L}$ and is not in agreement with the permissible limit of discharge of $125-1000 \mathrm{mg} / \mathrm{L}$ [5] as a result of high organic load from fleshings and trimmings from the beamhouse operations [46]. Over-application of high BOD effluents on land can create anaerobic conditions in the soil. Prolonged oxygen depletion will reduce the soil microorganisms' capability to break down the organic matter in the effluent that may lead to noxious odour generation and surface and ground water pollution.

\section{Detoxification Potentials of Polysiloxane Immobilized Ligand Systems on Raw Tannery Wastewater}

Six immobilized polysiloxane ligands were synthesized namely: PITSLS, PITLLS, PIMLS, PITSTLBLS, PITSMCBLS and PITLMCBLS, were employed in the detoxification of tannery wastewater as shown in Table 2.0 original adsorbents and 4.0, regenerated adsorbents. The effluent contained the following concentrations in ppm: $\mathrm{Cr}^{3+}$ (144.344), $\mathrm{Fe}^{3+}$ (49.420), $\mathrm{Cu}^{2+}$ (1.076), $\mathrm{Pb}^{2+}(1.766)$ and $\mathrm{Zn}^{2+}(0.238)$ 
respectively. Maximum percentage adsorption in $\mathrm{Cr}^{3+}$ was observed in PITSTLBLS (99.976) and the least value in PITLLS (99.925). These synthesized immobilized ligands were regenerated and re-employed for detoxification with a maximum adsorption value observed in PITLLS (99.936) and the least value been PITLMCBLS (96.377). The difference in the up-take capacity for PITLLS was calculated to be $3.578 \%$. $\mathrm{Fe}^{3+}$ percentage adsorption at maximum value was observed in PITSLS (99.816) with the least value in PITLLS (99.725). These adsorbents were regenerated and re-employed for detoxification, with maximum adsorption values in PITLLS and PITSTLBLS (99.725) and the least value in PITLMCBLS (99.043). The difference between the synthesized in the case of PITLMCBLS with the regenerated adsorbent was calculated to be $0.765 \%$.

$\mathrm{Cu}^{2+}$ percentage adsorption at maximum value was observed in PITSTLBLS (99.770) with least value in PITSLS (91.171). These adsorbents were regenerated and reemployed for detoxification, with maximum value in PITLLS (91.729), calculated difference with the synthesized product ( $94.729 \%$ ) gave $2.509 \%$. Consequently, the least value in the regenerated adsorbents was PITLMCBLS (75.929) calculated difference with the synthesized (87.398 \%) gave $21.469 \%$.

$\mathrm{Pb}^{2+}$ percentage adsorption at maximum value was observed in PITSTLBLS (95.470) with least value in PITSLS (91.053). These adsorbents were regenerated and reemployed for detoxification, with maximum adsorption value observed in PITLLS (82.276) with least value in PITLMCBLS (56.172). The calculated differences in PITLLS and PITLMCBLS was 9.457 and 39.015 respectively.

$\mathrm{Zn}^{2+}$ percentage adsorption at maximum values were observed in PITLLS, PIMLS, PITSTLBLS, PITSMCBLS and PITLMCBLS (100.00), with least value PITSLS (90.336). These adsorbents were regenerated and re-employed for detoxification with a maximum adsorption value observed in PITLLS (91.597) with the least value PITSMCBLS (75.210). The calculated differences for PITLLS and PITSMCBLS were 8.403 and $24.79 \%$ respectively.

The general performance of the synthesized adsorbents for all the metal ions $\left(\mathrm{Cr}^{3+}, \mathrm{Fe}^{3+}, \mathrm{Cu}^{2+}, \mathrm{Pb}^{2+}\right.$ and $\left.\mathrm{Zn}^{2+}\right)$ were observed to have a maximum percentage range of adsorption 100.00 with a least value 91.053. Consequently, the regenerated adsorbent gave a maximum adsorption range of 99.936 with a least value of 56.172. The decrease in metal ion adsorption could be attributed to leaching and degradation of the functionalized ligand groups from the siloxane network [47] and the in-availability of the reactive sites or saturation of binding sites possibly occupied by the metal ions in solution [48] in the case of the regenerated adsorbents.

\section{Detoxification Potentials of Polysiloxane Immobilized Ligand Systems in Buffered $(\mathrm{Ph}$ 6.0) Tannery Wastewater}

Six immobilized polysiloxane ligands were synthesized namely: PITSLS, PITLLS, PIMLS, PITSTLBLS, PITSMCBLS and PITLMCBLS, and were employed in the detoxification of tannery wastewater buffered to $\mathrm{pH} 6.0$ in Table 3.0. The effluent contained the following concentrations in ppm: $\mathrm{Cr}^{3+}$ (144.344), $\mathrm{Fe}^{3+}$ (49.420), $\mathrm{Cu}^{2+}$ (1.076), $\mathrm{Pb}^{2+}$ (1.766) and $\mathrm{Zn}^{2+}(0.238)$. Maximum percentage adsorption of $\mathrm{Cr}^{3+}$ was observed in PITLLS (99.988) and the least value in PITLLS (99.925), maximum percentage adsorption in $\mathrm{Fe}^{3+}$ was observed in PITSMCBLS (99.848) and the least value in PITSLS (99.263)., maximum percentage adsorption in $\mathrm{Pb}^{2+}$ was observed in PITLMCBLS (99.320) and the least value in PIMLS (52.434)., maximum percentage adsorption in $\mathrm{Cu}^{2+}$ was observed in PITLMCBLS (99.628) and the least value in PITSLS (99.907)., maximum percentage adsorption in $\mathrm{Zn}^{2+}$ was observed in PITLLS (100.000) and the least value in PITSTLBLS (91.596).

\section{Conclusion}

Leather industries contribute immensely in the growth of a nation through foreign exchange earnings with attendant pollution to the environment by the discharge of untreated wastewater from the tanneries. Samples of wastewater collected from Challawa Industrial Estate were subjected to some physico-chemical analysis and the results were above the standard permissible limits of discharge. This prompted the use of polymeric modified surfaces with excellent thermal, mechanical and chemical stability properties such as polysiloxane immobilized with ligands as a recyclable extractants for heavy metals. These immobilized ligand systems were synthesized directly by sol gel/chemical modification namely: PITSLS, PITLLS, PIMLS, PITSTLBLS, PITSMCBLS and PITLMCBLS and used in their pure and regenerated matrices for detoxification of raw and buffered tannery wastewater. The results obtained shows that, they have good adsorption potentials for the selected heavy metals and can be used in the tannery for detoxification process.

\section{References}

1. Sreeram KJ, Ramasami T (2003) Sustaining Tanning Process through Conservation, Recovery and Better Utilization of Chrome. Resources and Conservation Recycling 38(3): 185-212.

2. Hafez AI, El-Manharawy MS, Khed MA (2002) Reverse Osmosis Membrane Removal of Untreated Chromium from Spent Tanning Effluent. A pilot-Scale Study, Part II. 
Desalmination 144(1-3): 237-242.

3. Geremew LT, Tekalign KG (2017) Impacts of Tannery Effluent on Environments and Human Health: A Review Article. Journal of Environment and Earth Science 7(3): 88-97.

4. Khan SR, Kawaja MA, Khan AM, Gani H, Kazmi S (1999) Environment al Impacts and Mitigation Costs Associated with Cloth and Leather Exports from Pakistan. IUCNP to IISD Canada for the IISD/IUCN/IDRC Project on Capacity for Trade and Sustainable Development in Developing Countries, Islamabad.

5. Islam BI, Musa AE, Ibrahim EH, Salma AA, Sharafa, et al. (2014) Evaluation and Characterization of Tannery Wastewater. Journal of Forest Products and Industries 3(3): 141-150.

6. Puntener AG (1995) Wet-White Leather Processing: New Combination Tanning System. Journal of American Leather Chemists Association 90: 206.

7. Verheijen LAHM, Weirsema D, Hwshoffpol LW, Dewit J (1996) Live-Stock and the Environment: Finding a basic Balance Management of Waste from Animal Product Processing. International Agriculture Centre, Wageningen. The Netherlands.

8. Durai G, Rajasimman M (2011) Biological Treatment of Tannery Wastewater-A Review. Journal of Environmental Science and Technology 4(1): 1-7.

9. Muthukkauppan M, Parthiban P (2018) A Study on The Physicochemical Characteristics of Tannery Effluent Collected from Chennai. International Research Journal of Engineering and Technology (IRJET) 05(03): 24-28.

10. Jenkins R, Barton J, Hesselberg J (2004) The Global Tanning Industry: A Commodity Chain ApproachEnvironmental Regulation in the New Global Economy. The Impact on Industry and Competitiveness, Edward Elga, pp: 157-172.

11. Bhuiyan MAH (2010) Investigation of the Possible Sources of Heavy Metal Contamination in Lagoon and Canal Water in the Tannery Industrial Area in Dhaka, Bangladesh. Environ Monit Assess 175(1-4): 633-649.

12. EPA (1976) Assessment of Industrial Hazardous Waste Practices in Leather Tanning and Finishing Industry. SCS Engineers, US.

13. EPA (1982) Development Document for Effluent Limitations Guidelines and Standards For The Leather Tanning And Finishing Point Source Category. US Environmental Protection Agency, Research Triangle
Park, NC.

14. Nandy T, Kaul SN, Shastry S, Manivel W, Deshpande CV (1999) Wastewater Management in Cluster of Tanneries in Tamilnadu through Implementation of Common Treatment Plant. Journal of Science and Industrial Research 58: 475-516.

15. Kongjao S, Damronglerd S, Hunsom M (2008) Simultaneous Removal of Organic and inorganic Pollutants in Tannery Waste Water Using Electrocoagulation Technique. Korean Journal of Chemical Engineering 25: 703-709.

16. Stoop MLM (2003) Water Management of Production System Optimised by Environmentally Oriented Integral Chain Management: A case Study of Leather Manufacturing in Developing Countries. Technovation 23(3): 265-278.

17. Bienkiewicz K (1983) Physical Chemistry of Leathermaking. Krieger Publishing Co., Malabar, FL.

18. Igwe JC, Abia AA (2007) Adsorption isotherm studies of $\mathrm{Cd}$ (II), $\mathrm{Pb}$ (II) and $\mathrm{Zn}$ (II) ions Bioremediation from Aqueous solution using unmodified and EDTA-modified maize cob. Electronic Journal of biotechnology 32(1).

19. Mohammad MN, Nwaedozie JM (2012) Application of Marine Biomass for the removal of metals from industrial wastewater. Greener Journal of Physical Sciences 1(1): 36-44.

20. Igwe JC, Abia AA (2006) A bioseparation process for removing heavy metals from waste water using biosorbents. African Journal of Biotechnology 5(12): 1167-1179.

21. Luter L, Akaahan Terngu J, Attah S (2011) Heavy metals in soils of auto- mechanic shops and refuse dumpsites in Makurdi Nigeria. Journal of Applied Science and Environmental Management 15(1): 207-210.

22. Jahan MAA, Akhtar N, Khan NMS, Roy CK, Islam R, et al. (2014) Characterization of Tannery Wastewater and Its Treatment by Aquatic Macrophytes and Algae. Bangladesh Journal of Science and Industrial Research 49(4): 233-242.

23. El-Ashgar NM (2009) Extraction and Preconcentration Capacity of Bi-functionalized Diamine-Thiol Polysiloxane Immobilized Ligand System towards Some Divalent Cations. Journal of the Irannian Chemical Society 6(4): 823-830.

24. Ahmed K (2008) The Kano Physical Environment. 
25. Akan JC, Abdulrrahaman FI, Ogugbuaja VO, Reuben KD (2009) Study of the Physico-Chemical Pollutants in Kano Industrial Areas, Kano State, Nigeria. Journal of Applied Science 4(2): 89-102.

26. Danazumi S, Bichi MH (2010) Industrial Pollution and Implication on Source of Challawa River in Kano, Nigeria. Int Journal of Engineering and Technology IJET-IJENS 10(1): 76-81.

27. Mohammad HI, Mafizu R, Fahmidah UA (2010) Determination of Total Dissolved Solid (TDS) Assessment of Water Quality and Impact of Effluents from Fertilizer Factories to the Lakhya River International Journal of Water Resources and Environmental Engineering 2(8): 208-221.

28. Ademoroti CMO (1996) Standard Methods for Water and Effluents Analysis. Foludex Press LTD., Ibadan.

29. Balasubramanian S (1999) Characterization of Tannery effluents and the Correlation between TDS, BOD, and COD. Journal of Environmental Science and Health, Part A 34(2): 461-478.

30. Shugaba A, Wuyep PA, Nok AJ, Ameh DA, Lori JA (2010) Bioremediation of Hexavalent Chromium and Tannic Acid in Synthetic Tannery Waste Water using Free and Calcium Alginate-Immobilized Spores and Mycelia of Aspergillus niger and Aspergillus parasiticus. Bioremediation Journal 14(3): 142-149.

31. El-Nahhal IM, El-Ashgar NM, Chehimi MM, Bargiela P, Maquet J, et al. (2003) Metal uptake by porous iminobis (N-2-aminoethylacetamide)-modified polysiloxane ligand system. Microporous Mesoporous Materials 65(23): 299-310.

32. Salman MS, Nizam ME (2006) Preparation of Immobilized Polysiloxane Imino(2-aminoethylacetamide) and its Application. The Islamic University Journal Series of Natural Studies and Engineering 14(1): 37-50.

33. Nizam ME, Abdel-Latif MS (2008) Synthesis and Application of a New Polysiloxane Immobilized Macrocylic Ligand System. Analytical Letters 41(17): 3074-3087.

34. Ezeh EC, Ukoha PO, Bulus H, Nweze BN, Nwagu NL, et al. (2019) Adsorption Isotherms and Kinetics Studies of $\mathrm{Pb}^{2+}$ and $\mathrm{Cu}^{2+}$ Sorption by Semicarbazide Immobilized Polysiloxane as Material for Water Purification. Anachem Journal 9(1): 1652-1664.

35. Mohammad Ali AS, Abdul Razak N, Ab Rahman I (2012) Study on the Preparation of a Sol-Gel Sorbent Based
Thiosemicarbazone for Selective Removal of Heavy Metal Ions. World applied sciences journal 16(8): 10401047.

36. Bernard E, Jimoh A (2013) Adsorption of $\mathrm{Pb}, \mathrm{Fe}, \mathrm{Cu}$, and $\mathrm{Zn}$ from Industrial Electroplating Wastewater by Orange Peel Activated Carbon. International Journal of Engineering and Applied Sciences 4(2): 95-103.

37. Onyeji LI, Aboje AA (2011) Removal of Heavy Metals from Dye Effluent using Activated Carbon Produced from Coconut Shell. International Journal of Engineering Science and Technology 3(12): 8238-8246.

38. Horsfall MJ, Abia AA, Spiff AI (2006) Kinetic Studies on the Adsorption of $\mathrm{Cd}^{2+}, \mathrm{Cu}^{2+}$ and $\mathrm{Zn}^{2+}$ Ions from Aqueous Solutions by Cassava (Manihotesculenta) Tuber Bark Waste. Journal Bioresource Technology 97(2): 283-291.

39. Vasanth Kumar K (2006) Linear and Non-Linear Regression Analysis for the Sorption Kinetics of Methylene Blue onto Activated Carbon. Journal of Hazardous Materials 137(3): 1538-1544.

40. Richard D, Walter L (2013) The Framework for Leather Manufacture. World Trades Publishing Limited, USA, pp: 89-94.

41. Kurt U, Apaydin O, Gonullu MT (2007) Reduction of COD in Wastewater from an Organized Tannery Industrial Region by Electro-Fenton Process. Journal of Hazardous Materials 143(1-2): 33-40.

42. Mandal T, Dasgupta D, Mandal S (2010) Treatment of Leather Industry Wastewater by Aerobic Biological and Fenton Oxidation Process. Journal of Hazardous Materials 180(1-3): 204-211.

43. Song Z (2000) Sedimentation of Tannery Wastewater. Water Resources 34(7): 2171-2176.

44. Haydar S, Aziz JA (2009) Characterization and Treatability Studies of Tannery Wastewater using Chemically Enhanced Primary Treatment (CEPT): A Case Study of Saddiq Leather Works. Journal of Hazardous Materials 163(2-3): 1076-1083.

45. Anonymous WHO (2002) Water Pollutants: Biological Agents, Dissolved Chemicals, Non Dissolved Chemicals, Sediments, Heat, WHO CEHA, Amman, Jordan.

46. Ogabiela EE, Agunwa UB, Lawal FA, Owoeye LD (2007) Analysis of Tannery Effluents from the Confluence of Discharge Point at Sharada Industrial Estate in Kan, Nigeria. Journal of the Chemical Society of Nigeria 32(2): 17-23. 
47. Issa ME, Basheer AE, Kamal ARS, Nizam ME, Ahmed ME (2002) Polysiloxane-Immobilized Triamine Ligand System, Synthesis and Applications. Phosphorus, Sulfur, and Silicon and the Related Elements 177(3): 741-753.
48. Papita S, Shamik C, Gupta I, Kumar R (2010) Assessment on the Removal of Malachite Green using Tamarind Friut Shell as Biosorbent. Clean Soil Air Water 38(5-6): 437445.

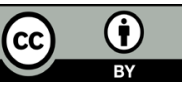

